\title{
Algunos aspectos que se deben tener en cuenta en materia de protección a los usuarios de la actividad aseguradora
}

\author{
Marco Antonio Ortega Piana*
}

\section{Introducción}

El 2 de setiembre del 2010 fue publicada en el diario oficial El Peruano la Ley 29571 -Código de Protección y Defensa del Consumidor; en lo sucesivo, Código de Consumo-, ley que, conforme a su cuarta disposición complementaria final, entró en vigencia el 2 de octubre del mismo año.

El objeto de estas líneas es asociar las disposiciones del Código de Consumo con normas que regulan ciertos aspectos de la actividad aseguradora, de manera particular en lo relativo a la información que la empresa aseguradora debe proporcionar al usuario (con este término nos referimos tanto al asegurado como al beneficiario del seguro, de ser el caso). Postulamos la tesis de que, en materia de promoción del acceso a la información y transparencia, las regulaciones expedidas por la Superintendencia de Banca, Seguros y AFP (en lo sucesivo, SBS) han antecedido de manera amplia a lo que dispone actualmente el Código

* Quien suscribe es miembro de la Defensoría del Asegurado -organismo autónomo de la Asociación Peruana de Empresas de Seguros-y, aunque en la actualidad desempeña su presidencia pro tempore, el contenido de este artículo no compromete a la Defensoría del Asegurado ni a la Asociación Peruana de Empresas de Seguros, sino que es de nuestra exclusiva responsabilidad. 
de Consumo. Incluso hasta podría considerarse que en algunos aspectos de este último ha habido cierto retroceso si lo compulsamos con el derogado régimen legal sobre protección al consumidor.

El tema nos resulta atractivo por diversas razones, no solo por su vinculación con nuestro actual desempeño profesional, sino porque hay de por medio un conjunto de aspectos asociados a conceptos jurídicos relacionados con nociones propias del derecho contractual, materia sobre la cual gira directa o indirectamente nuestra actividad docente, con la necesaria precisión de que la docencia no es sino un proceso de aprendizaje, de mutuo aprendizaje, a despecho del significado formal que la Real Academia Española le atribuye al término.

Hacemos constar, finalmente, que estas páginas corresponden en gran medida a lo que expusimos en el I Congreso Nacional de Derecho del Consumidor: "A un año de la puesta en vigencia del Código de Protección y Defensa del Consumidor", evento realizado en noviembre del 2011 y organizado por Ius et Praxis - revista oficial de la Facultad de Derecho de la Universidad de Lima-, a la cual agradecemos la deferencia de publicarlas en la presente edición.

\section{Comentarios sobre la materia, en relación con el Código de Consumo}

1. ¿Cuál es la finalidad del Código de Consumo? Conforme enuncia el artículo II de su título preliminar, es el acceso de los consumidores a productos y servicios idóneos, así como el goce de derechos y mecanismos efectivos de protección, reduciendo la asimetría informativa y corrigiendo, previniendo o eliminando las conductas y prácticas que afecten sus legítimos intereses.

Para fines de nuestro trabajo, interesa destacar ciertos aspectos: i) idoneidad del servicio; ii) mecanismos efectivos de protección de los derechos del consumidor; iii) reducción de la asimetría informativa; y iv) prevención de prácticas que atenten contra los derechos del consumidor.

2. La idoneidad está definida en el artículo 18 del Código de Consumo, y radica en la correspondencia que debe existir entre lo esperado y lo recibido por el consumidor, en función de lo ofrecido, la información proporcionada, el precio, etc., entre otras circunstancias que deben ser apreciadas en cada caso. 
Dado que el derecho protege la apariencia - en la medida, desde luego, en que corresponda a la confianza generada, base de todo negocio, incluso (y en mayor medida) de las relaciones de consumo-, resulta manifiesto que la evaluación de lo que "espe$\mathrm{ra}^{\prime}$ un consumidor no debe realizarse in concreto, sino in abstracto, atendiendo a parámetros, esto es, aquello que cualquier persona puesta en el lugar del consumidor (un consumidor promedio) se hubiese podido representar, considerando un conjunto de circunstancias tanto subjetivas (edad, formación, experiencia de consumo, etc.) como objetivas (las circunstancias referidas en forma expresa por la ley). Estimamos, además, que se trata, en todo caso, de aquello que se presume que el consumidor espera; pues, al final, lo que cada quien se represente y que no ha trascendido (al exterior, a los otros, a la contraparte de manera puntual) no tiene relevancia jurídica, lo cual es el sustento para descartar las reservas mentales como un vicio de la voluntad en materia de celebración contractual.

En otras palabras, para los fines de activar los mecanismos de protección al consumidor, la ley debe considerar aquello que un consumidor razonable se hubiese representado y, por lo tanto, estuviese esperando. Así por ejemplo, si se nos ofrece un seguro que brinda protección en caso de robo de tarjeta de crédito y lo contratamos, no nos resultaría aceptable que, producido el robo, se nos niegue cobertura con el argumento de que el siniestro no corresponde a un robo sino a un hurto, porque el lenguaje jurídico y legislativo no es necesariamente el lenguaje común o el empleado en una campaña informativa o de ventas. De manera que bien puede sostenerse que el consumidor promedio o razonable se representó que gozaría de una cobertura que se activaría una vez que un tercero se apoderase ilegítimamente de la tarjeta, usando o no usando violencia o intimidación. Empero, dejamos constancia de que la respuesta final - tratándose del ejemplo propuesto- dependerá, en todo caso, de qué es lo que se le informó con exactitud al usuario del servicio y qué es lo que se expresó en la póliza correspondiente, sea en las condiciones de cobertura, sea en las exclusiones.

3. En lo que se refiere a los mecanismos efectivos para proteger los derechos del consumidor, la legislación comentada contiene dis- 
posiciones específicas para que este no se vea afectado por prácticas comerciales coercitivas o políticas discriminatorias, estableciendo una serie de competencias del Instituto Nacional de Defensa de la Competencia y de la Protección de la Propiedad Industrial (Indecopi) sobre el particular. Con relación a estos mecanismos protectores, resulta pertinente el contenido de los literales g), h) e i) del inciso 1.1. del artículo 1 del Código de Consumo, en cuanto que el derecho de protección de los derechos del consumidor implica "procedimientos eficaces, céleres o ágiles, con formalidades mínimas, gratuitos o no costosos, según sea el caso, para la atención de sus reclamos o denuncias antes las autoridades competentes", así como el derecho a ser escuchado "a fin de defender sus intereses por intermedio de entidades públicas o privadas en defensa del consumidor" y el "derecho a la reparación y a la indemnización por daños y perjuicios conforme a las disposiciones del presente Código y a la normativa civil sobre la materia", respectivamente.

Así, en materia de seguros, uno de estos mecanismos efectivos - previsto por la SBS - radica en la Defensoría del Asegurado (en lo sucesivo, Defaseg), organismo autónomo de la Asociación Peruana de Empresas de Seguros (en lo sucesivo, Apeseg), ${ }^{1}$ cuyo reglamento establece un procedimiento ágil y gratuito para la atención de los reclamos que puedan someter a su conocimiento los usuarios de seguros privados (destacamos "puedan", pues se trata de una competencia de naturaleza voluntaria a la cual puede recurrir el asegurado). Lo resuelto en un caso particular por la Defaseg es vinculante para la empresa aseguradora, y el reclamante mantiene la posibilidad de recurrir a otras instancias si estima que un pronunciamiento es desfavorable para sus intereses.

4. En lo relativo a la reducción de la asimetría informativa, debe partirse del hecho cierto de que es usual que esta última se presente entre el proveedor del producto o servicio y el consumidor, dado que el primero posee mayor y mejor información sobre los productos o servicios, más aún cuando se trata de actividades que demandan una determinada especialización, como ocurre en el

1 No confundir con la Defensoría del Asegurado que opera para fines de la seguridad social (EsSalud). 
ámbito de la industria aseguradora. Por lo tanto, sobre la base de que se garantiza legalmente la configuración de mecanismos efectivos para proteger los derechos del consumidor, está previsto todo un régimen de transparencia, acceso a la información y deberes de información precisos y puntuales. En cuanto al acceso a la información, el Código de Consumo se sujeta, entre otros (artículo V de su título preliminar), a los principios de soberanía del consumidor (el régimen normativo pretende o está orientado a que el consumidor adopte decisiones libres e informadas, que son las que interesan finalmente para el desarrollo del mercado), transparencia (accesibilidad a la información veraz y apropiada) y buena fe (confianza y lealtad, atendiendo a las circunstancias y características de la contratación).

Así, tratándose de la información relevante que debe ser proporcionada por el proveedor del producto o servicio, el inciso 2.2. del artículo 2 del Código de Consumo establece que ella debe ser veraz, suficiente, comprensible, apropiada, oportuna, accesible y ser brindada en idioma español. Interesa destacar lo relacionado con que sea suficiente, comprensible, oportuna y accesible. Así por ejemplo, en materia de seguros grupales o colectivos, en la medida en que son contratos predispuestos y sujetos además a un régimen de cláusulas generales de contratación, la norma prevé que las aseguradoras están obligadas a informar, en determinada oportunidad y forma, sobre las condiciones más significativas o relevantes de la póliza contratada, entre ellas sobre los riesgos asegurados o el régimen de exclusiones. La normativa también prevé que la redacción de la póliza, de su condicionado, debe ser sencilla y permitir su comprensión.

5. Por último, en lo que concierne a la prevención de prácticas atentatorias contra los derechos del consumidor, ella no solo se traduce en la declaración expresa de nulidad contenida en el inciso 1.3. del artículo 1 del Código de Consumo - la que se explica porque la renuncia habría sido prevista por la parte que predispuso el contrato, beneficiándose de ella, de manera que no habría habido una efectiva voluntad de renuncia por parte del consumidor-, sino en el hecho de que hay normativa orientada a impedir que se generen prácticas abusivas. En el campo de la industria aseguradora puede destacarse, por ejemplo, la normativa relativa al 
rechazo de otorgamiento de cobertura en caso de siniestro, la cual prevé que dicho rechazo debe estar necesariamente sustentado en los medios probatorios que correspondan, de manera que sobre la base de ellos pueda cuestionarse o impugnarse, lo que implica al final que esté proscrito un rechazo unilateral, en el sentido de que sea inmotivado. También cabe destacar la figura del denominado "siniestro consentido", que armoniza con los temas comentados, pues trata de evitar, por disposición legal expresa, que la falta de pronunciamiento de la aseguradora sobre la solicitud de otorgamiento de cobertura en caso de siniestro genere incertidumbre en el respectivo solicitante, de tal forma que el rechazo debe ser expreso y oportuno, dentro de cierto plazo, pues de lo contrario se entenderá que no ha operado o que la aseguradora "declina" invocarlo y que se debe, correlativamente, honrar el respectivo pago indemnizatorio.

\section{Comentarios sobre la materia, en relación con la normativa que regula la actividad aseguradora}

1. Desde 1996, la Ley 26702, Ley General del Sistema Financiero y del Sistema de Seguros y Orgánica de la Superintendencia de Banca y Seguros, rige las actividades de las empresas financieras y de seguros. Interesa, para nuestro trabajo, focalizarnos en lo que establece su artículo 326, sobre condiciones y contenido de las pólizas de seguros:

Las condiciones de las pólizas y las tarifas responden al régimen de libre competencia en el mercado de seguros, con sujeción a las reglas que contiene este capítulo.

Las pólizas deben establecer las condiciones de la cobertura de riesgos.

Adicionalmente, dichas pólizas deben cumplir con los requisitos mínimos siguientes:

1. Su contenido debe ajustarse a las disposiciones legales que norman el contrato de seguro;

2. Las condiciones generales, particulares y especiales de la póliza han de ser redactadas en lenguaje fácilmente comprensible;

3. Los amparos básicos y las exclusiones deben figurar en caracteres destacados; 
4. El monto de la prima;

5. En su caso, se precisará el número del registro oficial del corredor de seguros y la comisión que este ha de percibir, que se fija libremente por acuerdo entre el asegurador y el corredor de seguros (lo subrayado es nuestro).

Como se aprecia, aunque el texto legislativo data de hace más de quince años, están enunciados requisitos que son compatibles con las exigencias actuales del Código de Consumo. No olvidemos que en materia de protección al consumidor se pretende cautelar el acceso a productos y servicios idóneos, así como al goce de derechos y mecanismos efectivos de protección, reduciéndose la asimetría informativa y corrigiéndose, previniéndose o eliminándose las conductas y prácticas que afecten los legítimos intereses del consumidor. En función del principio de transparencia y para su actuación regular en el mercado (que presupone agentes económicos libres e informados, capaces de adoptar la mejor decisión de consumo en función de sus intereses), el inciso 2.2. del artículo 2 del Código de Consumo establece que la correspondiente información debe ser veraz, suficiente, comprensible, apropiada, oportuna, accesible y brindarse en idioma español.

2. Pero el tema no se agota en la Ley 26702, sino que se extiende a las diversas normativas expedidas por la SBS, de las cuales nos interesa destacar principalmente, y para efectos del presente trabajo, dos de ellas: i) el Reglamento de Pólizas de Seguro y Notas Técnicas (en adelante, el Reglamento), aprobado por Resolución SBS 1420-2005, y sus sucesivas modificaciones; y ii) las normas sobre rechazo de siniestros, aprobadas por Circular S-610-2004.

3. El Reglamento dispone que, sin perjuicio de las exigencias establecidas en el artículo 326 de la Ley 26702 respecto al contenido de las pólizas, estas deben enunciar, al menos, entre otros aspectos (artículo 2): los deducibles, franquicias, coaseguros y similares a cargo del asegurado; las causales de resolución; el procedimiento y los requisitos mínimos para la solicitud de cobertura, y la definición de los términos relevantes utilizados en la propia póliza. En lo relacionado con la información relevante que debe proporcionar el proveedor del producto o servicio, el inciso $2.2 \mathrm{del}$ artículo 2 del Código de Consumo establece que aquella debe ser suficiente, comprensible, oportuna y accesible. 
¿Qué es lo que no debe contener una póliza de seguros? De acuerdo con el artículo 3 del Reglamento, entre otros aspectos: cláusulas de redacción ambigua o imprecisa; cláusulas que sean incompatibles con la buena fe o la equidad; y cláusulas que deriven en la pérdida de derechos indemnizatorios por incumplimiento de cargas injustificadas respecto al siniestro en relación con cual se solicita cobertura indemnizatoria. Desde un análisis civilista de estas prohibiciones, puede señalarse que al ser el contrato de seguro uno predispuesto, esto es, redactado en mayor o significativa medida de manera unilateral por la denominada parte "fuerte", que es la aseguradora - la cual goza además de una inocultable asimetría informativa en su favor (por el solo hecho de su conocimiento especializado, tratándose de la actividad aseguradora) -, lo que se prohíbe reglamentariamente no es sino lo que se conoce como "cláusulas abusivas" o "disposiciones vejatorias". En consecuencia, puede afirmarse que la póliza no debe contener disposiciones que, en general, no concuerden con la regla de la buena fe contractual; en caso contrario, el pretendido pacto será ineficaz.

Podrá discutirse si la violación a la regla de la buena fe implica una invalidez estructural o no estructural del respectivo pacto. Nos inclinamos a considerar que por tratarse de un tema contextual y en el cual es el propio consumidor o asegurado el llamado a manifestarse en primer lugar, se está ante una invalidez funcional u operativa, lo cual debería derivar en la inoponibilidad, ineficacia, del pacto, antes que en su invalidez. Empero, hay que admitir que el tema resulta opinable, pues también se postula que en determinadas materias el derecho no puede admitir la generación (y no solo la exigibilidad) de ciertos pactos, por lo que no se les reconoce existencia.

Sin perjuicio de los aspectos generales de contenido contractual, el Reglamento diferencia además el régimen aplicable a los seguros individuales, del régimen de los seguros de grupo o colectivos. Según la propia definición normativa (inciso j) del artículo 2 del Reglamento), son seguros de grupo o colectivos aquellos que se caracterizan por cubrir, mediante un solo contrato, a múltiples asegurados que integran una colectividad homogénea. Así, estos seguros permiten diferenciar entre lo que bien puede 
denominarse el "contratante no asegurado" y el "asegurado no contratante". Mediante un endoso y dependiendo del tipo de riesgo asegurado, el contratante no asegurado es el beneficiario del seguro y, en consecuencia, el legitimado para cobrar la indemnización. Así sucede, por ejemplo, cuando los bancos tienen contratadas pólizas en las que incorporan a sus clientes financieros, a quienes conceden créditos, como ocurre usualmente con las tarjetas de crédito: en los correspondientes contratos de crédito o de concesión de tarjeta de crédito consta la autorización del cliente al banco para que este lo incorpore en una póliza de seguro, asumiendo el pago de la prima correspondiente. Hay también ciertas situaciones atípicas en las que el cliente no es incorporado en una póliza contratada previamente por la respectiva empresa financiera, sino que aquella es contratada formalmente por esta última, pero a nombre del cliente, de manera que este asume la condición de "contratante asegurado" (endosando, luego, los derechos expectaticios de indemnización a la empresa financiera). Empero, más allá de ello, la realidad demuestra que a este cliente se le debe aplicar el régimen del "asegurado no contratante", pues en los hechos está en dicha situación.

¿Qué interesa destacar, tratándose de seguros grupales o colectivos, en materia de protección de los intereses del consumidor o usuario del sistema de seguros?

En el Reglamento se dispone, entre otros aspectos, que si los seguros son contratados a través de empresas del sistema financiero, los errores $\mathrm{u}$ omisiones de estas son errores $\mathrm{u}$ omisiones de las aseguradoras; también, que las comunicaciones de los asegurados a las empresas del sistema financiero tienen el mismo efecto que el que se desprendería de las que se hubiesen dirigido directamente a las aseguradoras. Esta disposición tiene particular relevancia porque la empresa del sistema financiero se convierte en un canal de comercialización de la empresa aseguradora, lo cual hace lógico que esta asuma los riesgos derivados de dicha actuación, dado que está en mejor situación de prevenirlos, adoptando las medidas más adecuadas para minimizar cualquier inconveniente que pudiera generarse, pues no siempre hay comunicación directa e inmediata entre la aseguradora y el asegurado no contratante. 
Además, se establece que las aseguradoras deben entregar un certificado de seguro al tomador o contratante dentro de los quince (15) días desde la recepción de la solicitud del seguro, salvo que se haya rechazado dicha solicitud. En el certificado debe expresarse la información mínima que indica el Reglamento, como riesgos cubiertos, exclusiones y cláusulas adicionales aplicables, así como el derecho a solicitar una copia de la póliza. El certificado es finalmente para el asegurado, de manera que a través de aquel pueda conocer suficiente y oportunamente el régimen al cual está sujeto. La cuestión radica en determinar a quién compete la entrega del certificado en cuestión: ¿a la aseguradora o a la empresa contratante? Si bien el certificado se debe entregar formalmente a la empresa contratante, estimamos que eso resulta insuficiente y que a la aseguradora le corresponde verificar que dicha empresa replique la entrega a los asegurados no contratantes, $\mathrm{o}$, en todo caso, proceda a realizar su entrega de manera directa, dado que lo que interesa es informar oportuna y adecuadamente al asegurado sobre las condiciones de la póliza, máxime cuando las empresas financieras se desempeñan para estos efectos como canales de venta o comercialización de seguros, por lo que sus defectos y faltas son finalmente oponibles a la aseguradora misma. Sin perjuicio del indicado certificado (o de la póliza, según corresponda, cuando se está ante seguros individuales contratados con intermediación financiera), debe entregarse al asegurado o al contratante un resumen de información sobre riesgos cubiertos, exclusiones, causales de resolución, procedimiento y plazo para solicitar cobertura, mecanismos de solución de controversias, áreas responsables para atender reclamos, e información sobre la Defaseg, autorizándose - de ser el caso, por la extensión de la información - para hacerse la referencia puntual a la póliza.

Las exigencias normativas reseñadas brevemente son muy significativas para los seguros grupales o colectivos, puesto que el asegurado no forma parte del contrato de seguro, no es parte formal ni material conforme se conceptualiza en materia de contratación - dado que no declara voluntad para la contratación de la póliza ni es el centro de interés incidido directamente por los efectos contractuales-; se trata de un tercero que se encuentra en una situación sui géneris. En atención a que el asegurado no es 
parte del contrato, pero tiene un interés relacionado con este, se explica la exigencia de la SBS de que aquel debe ser informado sobre los principales términos y condiciones del contrato de seguro, más aún cuando la parte contratante (la empresa financiera) le traslada el costo económico de la contratación del riesgo asegurado. Desde una perspectiva de racionalidad económica, bien puede afirmarse que se ha generado un régimen de incentivo para que las aseguradoras cumplan con las obligaciones de información previstas en el Reglamento, ya que de omitir la entrega de la información correspondiente, esta no le será oponible al asegurado no contratante. Así por ejemplo, si no se le informó que debía reportar la ocurrencia del siniestro dentro de cierto plazo, no resultará legítimo el rechazo de cobertura que luego invoque la aseguradora por causa de presentación extemporánea, por más que el procedimiento de solicitud de cobertura esté absolutamente regulado en la póliza, dado que dicho pacto sólo es conocido entre la aseguradora y la parte contratante no asegurada. En consecuencia, si la aseguradora pretende hacer oponible la póliza (y sus condicionados) al asegurado no contratante, debe cuidar de observar las exigencias normativas de la SBS, esto es, debe proporcionar información suficiente y oportuna, conforme se exige actualmente en el Código de Consumo. De la misma manera, si la aseguradora no informó al asegurado sobre el régimen de exclusiones, entre ellas las preexistencias, si luego ocurre un siniestro (por ejemplo, muerte) derivado de una enfermedad preexistente, esto es, existente antes de la contratación de la póliza (por ejemplo, diabetes), la aseguradora no podrá rechazar otorgar la cobertura, pues el asegurado no contratante ignoraba el régimen de exclusiones. Todo esto se da sin perjuicio - de ser el caso- del tema de invalidez de la póliza por inexacta, falsa o incompleta declaración con ocasión de contratar, de conformidad con el artículo 376 del Código de Comercio, más allá de que pueda surgir el interesante debate académico sobre si dicha invalidez debe generarse más bien a título de anulabilidad por vicio de la voluntad, debate en el cual no debe perderse la perspectiva de que la estimación del riesgo es un tema esencial en seguros, contrato de buena fe por excelencia.

Puede concluirse, entonces, que las normas comentadas, más allá de ciertos reparos $\mathrm{u}$ observaciones que puedan suscitar en 
ciertas materias, concuerdan con las actuales previsiones contenidas en el Código de Consumo.

4. Por su parte, las normas sobre rechazo de siniestros (Circular S-610-2004, circular aplicable a empresas de seguros, referida al rechazo de siniestros; en lo sucesivo, la Circular), con el objeto de evitar arbitrariedades y prácticas inadecuadas en perjuicio de los intereses de los usuarios del sistema de seguros, establecen que las aseguradoras deben fundamentar el rechazo en pruebas que acrediten fehacientemente el motivo en que se basa. En la respectiva comunicación deberá informarse con detalle sobre la justificación del rechazo, adjuntando copia de las pruebas que lo sustentan, en particular cuando se trate de una exclusión de cobertura. Es claro que si el rechazo se sustenta en una previsión contractual, el incumplimiento de una obligación o la inobservancia de una carga, será suficiente la invocación de una de estas causas, la que fuere, siendo ya otra historia si dicho fundamento contractual resulta o no oponible al asegurado, conforme se ha tratado antes.

Sobre este último tema, conforme al criterio de la doctrina que informa al derecho de seguros, corresponde a la aseguradora probar la exclusión que ha invocado al denegar la cobertura (lo cual, como toda exclusión, se aplica restrictivamente), teniendo en cuenta que la prueba no puede consistir en la simple invocación de una circunstancia, sino que su configuración debe ser demostrable, esto es, la aseguradora debe estar en capacidad de probar que se incurrió en la exclusión, bajo la premisa (conforme al Reglamento) de que esta sea oponible tratándose del caso singular de los asegurados no contratantes. Expresado en otras palabras: para fines del rechazo, debe fundamentarse la razón, sea porque el contrato de seguro así lo establece o porque se ha presentado una determinada situación, acreditable, que lo justifica. Ahora bien, la obligación de tener que fundamentar el rechazo con medios probatorios que - según sea el caso- sean fehacientes no implica que, de contradecirse luego o de quedar posteriormente desautorizados, el rechazo haya sido arbitrario y se haya inobservado la exigencia de la circular anteriormente comentada, dado que lo que se pretende es que no se produzcan rechazos inmotivados de cobertura, de manera que las aseguradoras deben expresar (fundamentar) en su oportunidad las respectivas razo- 
nes, sin perjuicio de cualesquiera otras que se pudiesen generar posteriormente, dado que el rechazo es a determinada fecha $y$ sobre la base de la información disponible a esa fecha.

Si el rechazo de cobertura no cumple con las indicadas exigencias, debe entenderse que no se ha configurado, aplicándose (de ser el caso) la figura del "siniestro consentido", regulada en el artículo 332 de la Ley 26702, debiéndose diferenciar necesariamente si el siniestro demandaba o no de ajuste.

\section{Defensoría del Asegurado}

1. Como se dijo, la Defaseg es un organismo independiente de la Apeseg. Conforme a su reglamento, está orientada a la protección de los derechos de los asegurados o usuarios de los servicios del seguro privado contratados en el país, mediante la solución de controversias que se susciten entre aquellos y las empresas aseguradoras, diferencias que no tienen que ver con la calidad del servicio, sino con la cobertura de siniestros, es decir, con que si los rechazos comunicados por las aseguradoras son fundados o no. Así, la competencia de la Defaseg solo se relaciona con el pago de las indemnizaciones que pudiesen ser debidas conforme a lo contratado, y no se extiende a otras materias, como por ejemplo, la exigencia de una reparación por daños y perjuicios. El sometimiento a este organismo es voluntario para los usuarios de los servicios de seguros (quienes pueden recurrir a otra instancia, administrativa o jurisdiccional), y lo que resuelve, conforme a derecho, es vinculante para las aseguradoras en el caso concreto, por lo que estas deben acatarlo, a diferencia de los primeros, quienes pueden recurrir a otras vías o mecanismos para hacer valer sus pretensiones si lo resuelto les resulta desfavorable. En cualquier caso, los pronunciamientos de la Defaseg no constituyen precedentes vinculantes de carácter general, lo cual no impide la generación de determinados criterios o pautas interpretativas uniformes o, en otros casos, recurrentes.

Se trata de una auténtica "defensoría", pues pretende brindar una solución rápida, segura, confiable y gratuita a los usuarios del sistema de seguros, quienes no tienen la necesidad de invocar el derecho que resulte aplicable al caso, ni requieren de la inter- 
vención de un abogado que los patrocine. Los miembros o vocales de la Defaseg deben aplicar a los hechos invocados el derecho que resulte pertinente, atentos a que existe una asimetría informativa del usuario del seguro respecto a las aseguradoras y a que estas sí suelen ser asistidas por sus asesores legales. La aplicación del derecho pertinente se extiende incluso a las normas de protección al consumidor contenidas en el Código de Consumo, interesando en particular el principio pro consumidor, enunciado en el numeral 2 del artículo $\mathrm{V}$ de su título preliminar, que si bien está relacionado con la actuación estatal, para nada está impedido de regir en una competencia privada y voluntaria, máxime cuando también es de aplicación supletoria el artículo 1401del Código Civil, que dispone la interpretación más benigna para la parte no predisponerte de los contratos de adhesión o celebrados con arreglo a cláusulas generales de contratación.

2. En lo que concierne al reglamento de funciones de la Defaseg, interesa destacar los siguientes aspectos:

a) La Defaseg solo conoce y resuelve los reclamos que los usuarios de seguros privados sometan voluntariamente a su pronunciamiento, dentro de su ámbito de competencia.

b) El ámbito de competencia implica el cumplimiento de ciertos requisitos concurrentes: i) que la indemnización solicitada no exceda de US\$50,000 o su equivalente en moneda nacional; ii) que el siniestro haya ocurrido a partir del 1 de febrero del año 2000, fecha de inicio de las actividades de la Defaseg; y iii) que el reclamo sea interpuesto dentro del plazo de ciento ochenta (180) días desde la primera comunicación de rechazo de cobertura, es decir, el plazo no se computa desde el último pronunciamiento que pudiese expedir la aseguradora (en los casos de reconsideraciones que suelen plantearse).

c) El procedimiento de reclamo es gratuito y no requiere de intervención de letrado; de ser necesaria alguna pericia para resolver el reclamo interpuesto, esta se realiza - en razón de dicha gratuidad - con cargo al presupuesto de la Defaseg.

d) Recibido el reclamo, y habiéndose verificado el cumplimiento de los requisitos de admisibilidad, se corre traslado a la aseguradora por el plazo de cinco (5) días hábiles, para que remita obligatoriamente el expediente completo del siniestro -lo que 
incluye la respectiva póliza, así como la información o documentación complementaria solicitada-, plazo dentro del cual también puede comunicar sus respectivos descargos. Conforme a ello, las aseguradoras deben presentar la póliza, los documentos necesarios (de ser el caso), para que su contenido sea oponible al asegurado, y el expediente del rechazo, documentación indispensable para que el respectivo colegiado pueda resolver.

e) Vencido el plazo indicado (salvo prórroga excepcional), se cita a las partes, por única vez, a una audiencia de informes orales, para que sustenten sus posiciones y absuelvan las cuestiones que pudiesen ser formuladas por los vocales que conforman la Defaseg, determinándose con precisión las materias controvertidas.

f) Los reclamos son evaluados y resueltos con arreglo a derecho y sobre la base de lo que obre en el respectivo expediente, en un plazo máximo de treinta (30) días hábiles. Es excepcional que la Defaseg resuelva fuera de este plazo, pero de ocurrir así, la experiencia demuestra que ello obedece a la particular complejidad del reclamo, pues se tiene en cuenta el impacto que el pronunciamiento puede tener en la actividad aseguradora.

g) Contra lo resuelto procede reconsideración (revisión - según se expresa en el respectivo reglamento- en sentido lato), debiéndose indicar el motivo, vicio o error en que se sustenta el recurso, no pudiendo formularse un pedido de revisión general.

h) La Defaseg no puede actuar de oficio para conocer de un reclamo que no haya sido sometido a su conocimiento.

\section{Casos que se deben considerar, relativos a la protección que corresponde otorgar al consumidor o usuario de los servicios de seguros}

1. Con suma transparencia y para facilitar la formación de una cultura sobre el seguro, la Defaseg publica en su página web institucional (www.defaseg.com.pe) no solo sus informes anuales, que contienen un diagnóstico de los problemas advertidos en materia de seguros privados - en función de los reclamos recibidos- y 
sus recomendaciones relativas a la actividad aseguradora, sino las diversas resoluciones que expide (con la lógica reserva sobre la identidad de las partes) en ejercicio de sus funciones, lo cual permite apreciar (y calificar, desde luego) los criterios que emplea para resolver las controversias, los cuales no son necesariamente uniformes, como se observa de los votos en minoría, singulares o en discordia.

Tomando como referencia algunas de dichas resoluciones, nos interesa destacar los casos que siguen.

Alberto Arias es titular de una tarjeta de crédito de una tienda por departamentos, y durante varios meses ha pagado (como consta en sus estados de cuenta mensuales) un seguro de desgravamen. Arias fallece y sus herederos solicitan que la citada tienda haga efectivo el seguro, reclame cobertura y declare cancelada la deuda proveniente del uso de la tarjeta aplicando el importe indemnizatorio del seguro. Luego de unos días, los herederos son informados de que el seguro no otorgará cobertura porque la muerte de Arias obedece a una enfermedad ya diagnosticada (preexistente) a la fecha en que este tarjetahabiente fue incorporado como asegurado en la póliza contratada por la empresa financiera emisora de la tarjeta de crédito, supuesto que consta como exclusión en el condicionado general de dicha póliza. Los herederos expresan su extrañeza porque, habiéndose pagado con puntualidad la respectiva prima mensual, entienden que el seguro de desgravamen debería funcionar automáticamente, más aún cuando fue contratado para que cancele la deuda que hubiese quedado impaga en caso de fallecimiento del deudor.

Beatriz Ballester es cliente de una cadena de supermercados; ha pagado los respectivos estados de cuenta mensual, y en el importe que se le liquida mensualmente figura una suma algo diminuta y que corresponde al concepto "seguro de desgravamen". Un día queda imposibilitada para seguir trabajando, debido a una penosa enfermedad, y solicita que se aplique dicho seguro, que cubre, según publicidad de la cadena de supermercados, muerte natural y por accidente, así como imposibilidad para trabajar. Lo que se le comunica al final es que, no obstante los certificados y demás documentación presentada, no se extenderá cobertura, pues, según los términos de la póliza, la imposibilidad para trabajar 
debe ser diagnosticada conforme a las normas que sobre la materia aplican las empresas del Sistema Privado de Administradoras de Fondos de Pensiones. Ballester reclama porque en ningún momento ni en ningún documento se le informó sobre dicha exigencia, y además ha tenido que realizar una serie de trámites para gestionar y obtener los estudios y certificados que ahora, según manifiesta la aseguradora, son insuficientes.

Carmen Cáceres ha concertado un préstamo vehicular con un reconocido banco local. Según los términos y condiciones del préstamo, la cliente, por su cuenta y riesgo, autoriza al banco para que contrate un seguro contra todo riesgo para el vehículo, atendiendo a que sobre este se constituirá garantía en favor de aquel, por lo que a dicha institución le interesa asegurar el valor del vehículo en caso de pérdida o deterioro. Un día se produce un lamentable accidente de tránsito, producto del cual el vehículo sufre serios daños. Aunque Carmen Cáceres asienta la denuncia policial a las pocas horas - luego de reponerse de un serio ataque de nervios-, no se somete oportunamente al examen de alcoholemia ni comunica del accidente a la aseguradora. Luego de varios días, cuando solicita cobertura para reparar el vehículo, la aseguradora le manifiesta que no se la brindará al haber incumplido obligaciones señaladas expresamente en la póliza, entre ellas, comunicar del siniestro dentro de la hora de ocurrido a su central de emergencias, por lo que no solo se ha producido el fenecimiento de su derecho indemnizatorio, como está previsto de manera expresa en la póliza, sino que además ha incurrido en causal de resolución de contrato, pues los términos contractuales son de estricto e ineludible cumplimiento.

Daniel Dávila contrata un seguro de responsabilidad civil. Al solicitar el otorgamiento de cobertura se la niegan, según expresa la aseguradora en su comunicación de rechazo, porque a mérito de determinado endoso de la póliza, fueron modificadas las condiciones de cobertura. Dávila no sólo expresa que nunca solicitó el endoso, sino que este jamás le fue informado.

Elías Echegaray ha tomado un seguro de desempleo mediante una determinada empresa bancaria. Generado el siniestro indemnizable, solicita la respectiva cobertura, presentando al banco la 
información que le es requerida. Luego de dos meses, este le comunica que la aseguradora ha denegado el otorgamiento de cobertura.

2. Los casos enunciados son reales; quizá hay alguna licencia en el relato, pero corresponden a sendos reclamos ante distintas aseguradoras.

En el país, gran cantidad de seguros se contratan en el marco de operaciones crediticias de contenido predispuesto. Constituye política generalizada que en el estado de cuenta de las tarjetas de crédito se cargue determinada suma, algo módica, por concepto de seguro de desgravamen; para ello, en las condiciones aplicables al respectivo contrato de cuenta corriente - tarjeta de crédito (condiciones predispuestas) consta la autorización que el cliente extiende a la empresa financiera emisora de la tarjeta. También es política generalizada que en los contratos financieros de préstamo con garantía específica (mobiliaria o inmobiliaria) se establezca la obligación de contratar un seguro para la garantía, de manera que se prevenga su pérdida o deterioro; por lo general, esta obligación se complementa con la autorización, a la empresa financiera, para que contrate la respectiva póliza. Es más, incluso muchas aseguradoras venden pólizas a través de la intermediación de empresas financieras y no financieras, sean de vida, de accidentes, de robo domiciliario, etc. Estas empresas se configuran de hecho como agentes de venta de las aseguradoras, integrando, en muchos casos, un mismo grupo económico.

Desde la perspectiva del consumidor, del cliente ordinario de una entidad financiera, que adquiere un crédito personal vía tarjeta de crédito o por calificación especial, con el respaldo de una garantía real, dicho crédito está sujeto a una doble contratación predispuesta: a la concertada directamente con la empresa financiera (contrato de cuenta corriente - tarjeta de crédito y contrato de préstamo, según los casos que hemos referido) y, además, a la concertada por la empresa financiera con la aseguradora, con la precisión de que en este último caso el consumidor ni siquiera forma parte del contrato de seguro, sino que es un tercero que asume la condición de asegurado y que, por lo general, cede o endosa sus derechos indemnizatorios a favor de su acreedor: la 
propia contratante, la empresa financiera. Pero no se trata de cualquier tercero, pues este consumidor es quien paga la prima; por consiguiente, este consumidor, cliente ordinario de una entidad financiera, es quien asume al final el costo del seguro contratado conforme a sus "propias" instrucciones (adscritas, a su vez, a un contrato predispuesto por la contraparte). Por lo tanto, resulta manifiesto que debe existir un determinado régimen que garantice determinados aspectos para evitar abusos o arbitrariedades.

La práctica demuestra que las empresas financieras ya tienen contratadas pólizas grupales o colectivas en las que incorporan a sus clientes (asegurados no contratantes), pero muchas veces, y conforme a la autorización recibida, proceden a contratar un seguro particular o individual por suma suficiente respecto de los riesgos previstos, y además quedan autorizados a cobrar el importe correspondiente, dado que el asegurado (titular del interés asegurable) endosa o cede sus derechos indemnizatorios a favor de su acreedor crediticio. Esta contratación de seguros parte, en consecuencia, de la premisa conforme a la cual el cliente está obligado a mantener ciertos seguros durante la vigencia del préstamo, por lo que el seguro se configura como un medio de garantía.

Las legítimas y crecientes necesidades sociales han derivado en el progresivo abandono de la figura de la contratación paritaria o negociada, y son cada vez más las situaciones en las que el uso eficiente de los escasos recursos disponibles ha llevado a optar por la contratación masiva o predispuesta, donde los términos y condiciones están estandarizados y los márgenes de negociación son inexistentes o muy limitados. La contratación financiera y la contratación de seguros son, fundamentalmente, predispuestas. Conforme a la moderna concepción de la autonomía privada que supera a la clásica y casi todopoderosa autonomía de la voluntad-, en la regulación de la contratación predispuesta se trata de evitar llegar a situaciones que resulten intolerables. Debido a ello, no sólo terminan siendo aplicables las normas del Código Civil sobre las denominadas cláusulas abusivas, exorbitantes o vejatorias $-\mathrm{y}$ las pertinentes sobre el sentido de la interpretación a favor de la parte no predisponente-, sino también un conjunto de normas legales, con plena coherencia desde una perspectiva 
sistémica, entre las que podemos destacar los artículos 58, 377, 378 y 412 del Código de Comercio, el artículo 326 de la Ley 26702, la Resolución SBS 1420-2005 y, desde luego, al Código de Consumo, según el cual el consumidor no solo tiene derecho a información oportuna, suficiente, veraz, fácilmente accesible y relevante para tomar una decisión o realizar una elección de consumo que se ajuste a sus intereses, sino también a la protección de sus intereses económicos y, en particular, contra las cláusulas abusivas, métodos comerciales coercitivos y cualquier otra práctica análoga, y contra la información interesadamente equívoca sobre los productos o servicios; derechos, todos ellos, que tienen simetría con lo que corresponde a las obligaciones del proveedor.

Ya hemos destacado que la contratación de seguros en el marco de operaciones financieras o - en general - que sean predispuestas se suele realizar incorporando al cliente en una póliza de grupo o de carácter colectivo. Con relación a estas pólizas, el artículo 7 del Reglamento establece que las empresas aseguradoras están obligadas a emitir los certificados de seguro necesarios según el número de asegurados de la póliza, de acuerdo con la información mínima que al efecto se regula y que deberá ser concordante con la información brindada por el asegurado en la solicitud de seguro presentada por el tomador o contratante (intermediario de hecho por la autorización predispuesta para contratar) a la respectiva empresa. Dichos certificados de seguro deben ser entregados por las empresas aseguradoras a los tomadores o contratantes en un plazo máximo de quince (15) días calendario contados desde la fecha de recepción de la solicitud del seguro, salvo rechazo de esta (rechazo que se extiende a los asegurados no contratantes, conforme se ha destacado). Asimismo, se establece que, a solicitud de los asegurados, las empresas aseguradoras emitirán copia de la póliza correspondiente, incluyendo las condiciones generales, particulares, especiales y cláusulas adicionales que le sean aplicables, debiendo entregarla en un plazo máximo de quince (15) días calendario contados desde la fecha de recepción de la respectiva solicitud. El derecho del asegurado a solicitar copia de la póliza de seguro de grupo o colectivo debe figurar impreso en el certificado de seguro. 
Aunque la norma no lo diga en forma explícita, es evidente que si en el certificado debe constar el derecho del asegurado a solicitar una copia de la póliza, para que este haga efectivo su derecho debe conocerlo, lo cual presupone que dicho certificado le haya sido entregado. Este es un argumento que refuerza lo expresado, en el sentido de que debe entenderse que la entrega de los certificados no se agota cuando la aseguradora los proporciona a la empresa tomadora o contratante (más allá de que esta, al final, los entregue o no a los asegurados), sino que debe verificar (y asumir responsabilidad) que los certificados se entreguen, en efecto, a los asegurados (quienes poseen evidente legítimo interés); de lo contrario, la aseguradora podría resultar perjudicada al no poder oponer los términos y condiciones del contrato a quien simplemente no los conocía, más aún cuando el asegurado es quien asume el costo final del seguro al pagar las primas. Hay de por medio un criterio de equidad, un tema de eficiente empleo de recursos, pues la aseguradora está en la mejor posibilidad de exigir el cumplimiento de la entrega de los certificados, sin mayor costo, siendo más difícil -si no remoto (considerando el poder de negociación en una contratación masiva o predispuesta) - que el asegurado, el cliente financiero o el consumidor se lo pueda exigir a la empresa financiera tomadora o contratante de la póliza.

Sobre esta materia, en su informe final correspondiente al ejercicio 2009, la Defaseg manifiesta que

[...] ha recibido con sorpresa la posición de algunas compañías de seguros, según las cuales su obligación consiste únicamente en entregar el certificado de seguro al contratante o tomador del seguro, y que no es su responsabilidad si este luego no se lo entrega al asegurado. En otras palabras, sostienen que le pueden oponer al asegurado los pactos resumidos en el certificado desde el momento en que se lo remiten al tomador o contratante, sin importar si este cumplió - a su vez- con entregárselo al asegurado. Esta Defensoría considera que la SBS le ha impuesto a las compañías de seguros la obligación de entregar el certificado a fin de que el asegurado pueda tomar cabal conocimiento del seguro que lo ampara, por lo que le corresponde a la compañía de seguros - y no al contratante del seguro- verificar que el certificado se le entregue al asegurado. Con semejante interpretación, la compañía de seguros pretende trasladar al contratante, 
que puede ser un banco, una asociación u otra institución, obligaciones que emanan de la relación asegurado-asegurador, olvidando que la responsabilidad por el cumplimiento de dichas obligaciones, como es por ejemplo la de proporcionar información sobre los términos y condiciones del contrato, le es inherente a ella por su condición de empresa de seguros. ${ }^{2}$

De manera general, el artículo 9 del Reglamento establece que las empresas aseguradoras deberán entregar a los asegurados y/o contratantes, junto con la póliza o certificado de seguro - según el caso-, un resumen en el que consten de manera clara y breve los riesgos cubiertos y las exclusiones, las causales de resolución del contrato, el procedimiento y plazo para efectuar reclamos, los mecanismos de solución de controversias, las áreas de la empresa encargadas de atender reclamos de los usuarios - señalando su ubicación y teléfono-, así como la ubicación, teléfono y página web de la Defaseg. Cuando la amplitud de la información lo justifique, las empresas aseguradoras podrán remitirse a la póliza de seguro, debiendo indicar de manera expresa, en el resumen, el rubro a que se refiere dicha información y el número del artículo o cláusula correspondiente, a fin de que el asegurado y/o contratante tenga fácil acceso a las disposiciones ahí contenidas.

Del mismo modo que al evaluar los alcances del artículo 8, la referencia contenida en este artículo al asegurado y/o contratante no debe entenderse como indistinta, a uno o a otro, sino a ambos (pero, en cualquier caso, siempre al asegurado, si hubiese una disociación con la condición de contratante).

La práctica demuestra que, por cualesquiera razones, estas normas de protección no se cumplen siempre; el problema deriva en que, cuando surge un reclamo de cobertura, se pretende oponer pactos contractuales (de la póliza o de su condicionado aplicable) que el asegurado no conoce. Como se ha indicado, la regulación normativa sobre las pólizas grupales, o de aquellas grupales o no contratadas con la intermediación de empresas financieras, debe interpretarse en el sentido de que se garantice que los asegurados conozcan los términos y condiciones fundamentales

2 Informe final de la Defensoría del Asegurado, correspondiente al ejercicio 2009, disponible en la página web de dicha entidad (www.defaseg.com.pe). 
que regulan la relación de seguros y, en particular, las condiciones de cobertura y exclusiones aplicables. Hay de por medio un elemental tema de buena fe, un elemental criterio de justicia.

3. Retomemos los cinco casos expuestos al inicio. En el caso de Alberto Arias, si bien la enfermedad que explica su muerte se diagnosticó con fecha anterior a la oportunidad en que fue incorporado como asegurado en la póliza grupal contratada por la empresa financiera emisora de la tarjeta de crédito, y que en el tenor de la póliza consta en forma expresa que las enfermedades preexistentes implican una exclusión de cobertura, no es menos cierto que el cliente, el asegurado, el consumidor del servicio, jamás fue informado por la aseguradora, ni por la empresa financiera, sobre dicha situación, ya que nunca se le entregó un certificado de seguro ni un resumen de las principales condiciones de la póliza, de manera que no se le puede oponer la exclusión.

Conforme a lo señalado, el derecho a reclamar la indemnización no puede ser afectado, pero no por la razón estimada por los herederos del asegurado (pago de las primas), sino porque la exclusión pactada entre aseguradora y contratante (empresa financiera) no puede oponerse al asegurado no contratante si este no la ha conocido en forma oportuna. En ese sentido, dado que la aseguradora ha invocado la correspondiente exclusión (enfermedad preexistente) de cobertura, ella tiene la carga procesal no solo de acreditar la existencia de la exclusión y el cumplimiento de los requisitos para oponer válidamente el respectivo pacto, sino que también pueda oponerlo legítimamente por haberlo informado oportuna y adecuadamente, evitándose situaciones de abuso, por un lado, e indefensión, por otro lado.

Otro tema - que escapa a los alcances de este trabajo- es si las enfermedades preexistentes deben haber sido solo diagnosticadas o si deben, además, ser de conocimiento del asegurado, con lo que surge la cuestión de cómo acreditarlo. Para ello, habrá que sopesar los intereses comprometidos, ya que un seguro no corresponde a una relación de beneficencia, sino de previsión, de manera que la aseguradora otorga cobertura en función de que estimó determinado riesgo y no otro.

La solución precedente es la misma para el caso de Beatriz Ballester. No está en discusión que la póliza establezca, en efecto, 
que la imposibilidad para trabajar del asegurado sea diagnosticada conforme a las normas que sobre la materia aplican las empresas del Sistema Privado de Administradoras de Fondos de Pensiones; el problema radica en que dicha exigencia nunca le fue comunicada a Ballester. En este caso sí hubo entrega de un certificado de seguro, pero de su contenido no se extrae lo que es materia de controversia, ni de la manera más remota. Por lo tanto, la aseguradora debería otorgar cobertura; no puede ampararse en sus omisiones para pretender desligarse de su responsabilidad.

El caso de Carmen Cáceres presenta connotaciones especiales. En principio, es semejante a los dos primeros, en el sentido de que la aseguradora no logra acreditar que haya proporcionado a la asegurada - por tratarse de un seguro individual- copia de la póliza ni un resumen de sus principales condiciones, pese a que esta es quien ha pagado las primas correspondientes, más allá de la intermediación de la empresa financiera; en consecuencia, la aseguradora debe cumplir con otorgar la correspondiente cobertura. Pero el caso tiene, además, un aspecto que merece destacarse, muy asociado a lo ya tratado antes, sobre aquello que conforme al Reglamento debe contener la póliza y aquello que no debe contener: la póliza dispone, remitiéndose a su condicionado, que el asegurado debe cumplir ciertas obligaciones en caso de accidente vehicular: i) asentar la denuncia ante la autoridad policial de la jurisdicción y solicitar el examen de evaluación de daños; ii) someterse a la prueba de alcoholemia dentro de las cuatro horas siguientes; y iii) comunicar de inmediato el accidente a la aseguradora, dentro de la hora de ocurrido, a su central de atención (emergencias); requisitos cuyo incumplimiento implica no solo el automático perecimiento del derecho a obtener la indemnización pactada, sino la resolución del contrato por incumplimiento de obligaciones. En rigor, dilucidando conceptos jurídicos, las actividades que debe ejecutar el asegurado como consecuencia de un siniestro y para reclamar cobertura en su oportunidad, no son propiamente obligaciones (dado que las actuaciones comprometidas no buscan satisfacer el interés de la contraparte, esto es, de la aseguradora), sino cargas, como situaciones jurídicas subjetivas específicas estructuradas en función del interés de la asegurada, pues su observancia permitirá mantener o no su expectativa indemnizatoria. Conforme a lo anterior, dado que la sanción por 
inobservancia de las cargas es, en buena cuenta, la liberación de la aseguradora de su obligación de indemnizar, por la trascendencia de dicho efecto resulta esencial determinar, por un lado, si la aseguradora sufre o no un perjuicio real si la asegurada inobserva la carga y, por otro, si la omisión de la asegurada es gravemente culposa o dolosa, o si se trata de una falta de observación por culpa leve o levísima.

Debe considerarse que, conforme se ha destacado, el artículo 3 del Reglamento prohíbe que las pólizas contengan cláusulas de redacción ambigua o imprecisa, o que sean incompatibles con la buena fe o la equidad, o que establezcan la pérdida de derechos indemnizatorios por incumplimiento de cargas injustificadas respecto al siniestro con relación al cual se solicita cobertura indemnizatoria. Si bien el derecho reconoce el carácter vinculante de los contratos (principio elemental para fines del intercambio económico), la capacidad de crear y regular obligaciones y situaciones jurídicas se sustenta, en general, en la existencia de intereses dignos de tutela y protección jurídica. Por consiguiente, no puede negarse que una consecuencia tan grave, esto es, la pérdida de la expectativa indemnizatoria en el caso comentado, debe estar respaldada por algo que así lo explique, por elemental proporcionalidad, más aún cuando estas sanciones son establecidas en el marco de un contrato predispuesto, donde existe la posibilidad de que se incorporen pactos que puedan resultar contextualmente abusivos.

Si los términos de la póliza hubiesen sido oponibles a la asegurada, el rechazo de cobertura por el incumplimiento de las cargas sería legítimo, al menos en principio, pues la rigurosidad de los plazos pactados se justifica por las circunstancias, en el sentido de que se trata de asegurar la recuperación del vehículo - de allí el inmediato aviso a la policía y a la aseguradora - y descartar que se haya generado una situación de incremento de riesgo, por lo que se trata de eliminar o atenuar (en el limitado plazo de que se dispone, atendiendo a la metabolización del alcohol en la sangre humana) la posibilidad de dicho incremento.

Por último, queda desestimada cualquier resolución del contrato - menos unilateral o extrajurisdiccional- por incumplimiento de cargas y no de obligaciones, porque son estas últimas, 
y no las primeras, las estructuradas en función del interés del acreedor; en el presente caso, de la respectiva aseguradora. Conforme a ello, no corresponde que se resuelva el contrato por incumplimiento de lo que no es en estricto una obligación, aunque nada impide que se haya establecido un mecanismo con efectos resolutorios. No obstante, dado que las cargas se estructuran en función del interés de quien debe observarlas, sí corresponde, definitivamente, el perecimiento de la pretensión indemnizatoria del asegurado.

En el caso del asegurado Daniel Dávila, la cobertura debe ser otorgada porque el endoso invocado por la aseguradora no le fue informado. La regla en materia contractual es que los contratos no pueden ser modificados de manera unilateral, sino con el asentimiento de la contraparte, por más que el consentimiento pueda expresarse previamente. Ocurre que las pólizas de seguro contienen, en algunos casos, el acuerdo de las partes conforme al cual se autoriza a la aseguradora a modificar el régimen del contrato, mediante endosos, pero dicha modificación debe ser informada. Y cuando la aseguradora emite directamente el endoso de modificación, no basta la comunicación, sino que se requiere del asentimiento de la contraparte, y el endoso en cuestión equivale jurídicamente a una oferta de modificación contractual que requiere necesariamente de una aceptación. Si la póliza de Daniel Dávila hubiese sido una grupal o colectiva, en la que este no forma parte del contrato (asegurado no contratante), no hubiera sido suficiente el asentimiento del contratante no asegurado, sino que de todas maneras las modificaciones sobre las condiciones de cobertura le hubieran tenido que ser comunicadas por su condición de asegurado no contratante.

Por último, en el caso del asegurado Elías Echegaray, resulta aplicable la figura del "siniestro consentido", a la que ya nos hemos referido. De presentarse completa la documentación requerida para la calificación de la cobertura, la aseguradora dispone de un plazo perentorio para pronunciarse negativamente (de ser el caso), esto es, para rechazar el otorgamiento de cobertura, de conformidad con el artículo 332 de la Ley 26702; en caso contrario, ante la falta de pronunciamiento, queda obligada a otorgarla. Sobre el particular, resulta pertinente el inciso j) del 
artículo 3 del Reglamento, en cuanto dispone que las pólizas de seguro, además de las exigencias establecidas en el artículo 326 de la Ley 26702, deben contener como información mínima, entre otra, la indicación sobre el procedimiento para la reclamación de siniestros (esto es, para solicitar cobertura), lo cual incluye la identificación de toda aquella documentación o información que debe ser presentada a la aseguradora; de manera que desde un inicio se debe conocer qué se tiene que presentar para fines de cobertura, evitándose así dilaciones y arbitrariedades. Conforme a lo anterior, si se presenta la documentación completa requerida en la póliza y la solicitud de cobertura no es atendida en forma oportuna (regla general, dentro de los treinta (30) días siguientes), la consecuencia es que opera un "silencio positivo"; es decir, no habiendo rechazo, se entiende, para todo efecto legal, que el siniestro quedó consentido y debe ser indemnizado, en la medida, desde luego, en que se esté dentro del ámbito de aplicación de la cobertura contratada.

Atendiendo a lo anterior, la circunstancia de que la solicitud de cobertura y el posterior rechazo se hayan realizado a través de una empresa financiera, de la cual se ha valido la aseguradora, resulta al final irrelevante - por las razones comentadas al tratar sobre el régimen normativo contenido en el Reglamento-, pues las empresas financieras son para todo efecto una suerte de representante (comercial) de las aseguradoras - ejercen su representación oficiosa-, las que asumen sus "activos y pasivos", por lo cual la inacción de las financieras y/o de las aseguradoras no puede implicar una extensión de los plazos perentorios legales en perjuicio de los derechos del consumidor o usuario del servicio de seguros privados.

Además, conforme a la Circular, no debe olvidarse que el rechazo de cobertura debe estar fundamentado, por lo que no basta la simple negativa de extensión de cobertura - como se habría realizado en el caso comentado-, negativa que evidenciaría un rechazo arbitrario.

\section{Comentario final}

Los seguros son evidencia palpable de una cultura de previsión. La seguridad es un anhelo de todo individuo, por lo que en su búsqueda 
las personas suelen adoptar y concertar una serie de medidas para eliminar riesgos o reducir sus efectos.

Interesa a la propia industria aseguradora que los asegurados, consumidores o usuarios de los servicios de seguros privados sientan que sus intereses están resguardados, de manera que la confianza no se afecte por omisiones operativas que deben y pueden ser superadas brindando un servicio idóneo y sin que represente necesariamente mayores costos. Los seguros, más aún cuando están contractualmente coligados a operaciones crediticias, en estricto cumplimiento de las normas reglamentarias y de la propia lógica del sistema, deben generar seguridad y razonable tranquilidad para los miles de clientes de las empresas financieras y de seguros.

\section{Bibliografía}

Castelo Matrán, Julio y José María Pérez Escacho (1981). Diccionario básico de seguros. $4 .^{\mathrm{a}}$ edición. Madrid: Mapfre S.A.

Informe final de la Defensoría del Asegurado, correspondiente al ejercicio 2009. <www.defaseg.com.pe>.

Ossa, Efrén (1963). Tratado elemental de seguros. Bogotá: Ediciones Lerner. 